\title{
Paclitaxel induces apoptosis in leukemia cells through a JNK activation-dependent pathway
}

\author{
Z.G. Peng', D.C. Liư ${ }^{2}$, Y.B. Yao', X.L. Feng ${ }^{3}$, X. Huang ${ }^{1}$, Y.L. Tang ${ }^{1}$, J. Yang ${ }^{1}$ and \\ X.X. Wang ${ }^{1}$ \\ 1'Department of Hematology, The First Affiliated Hospital, Guangxi Medical University, \\ Nanning, Guangxi, China \\ ${ }^{2}$ Department of Surgery, Beijing Xuanwu Hospital, Capital Medical University, \\ Xuanwu District, Beijing, China \\ ${ }^{3}$ Department of Functional Genomics, National Human Genome Center of China, \\ BDA, Beijing, China \\ Corresponding author: Z.G. Peng \\ E-mail: zhigangpengcn@126.com \\ Genet. Mol. Res. 15 (1): gmr.15013904 \\ Received August 12, 2015 \\ Accepted November 13, 2015 \\ Published March 11, 2016 \\ DOI http://dx.doi.org/10.4238/gmr.15013904
}

ABSTRACT. Paclitaxel (PTX) is a mitotic inhibitor widely used in chemotherapy for many types of cancers, including solid tumors and hematological malignancies. However, the molecular basis of the antiproliferation activity of PTX is not fully understood. In this paper, we focused on the role of c-Jun N-terminal kinase (JNK) pathways in PTXinduced apoptosis and proliferation inhibition. The effects of PTX were examined in human leukemia cell lines and patients' chronic lymphocytic leukemia (CLL) cells in relation to mitochondrial events, apoptosis, and perturbation of JNK activation using flow cytometry, siRNA, mitochondrial membrane potential determination, and western blotting. Exposure of cells to PTX at concentrations $\geq 10 \mathrm{nM}$ for 18 or $24 \mathrm{~h}$ resulted in a significant release of cytochrome $c$ from mitochondria to the cytosol, cleavages of procaspase 3 and poly (ADP-ribose) polymerase (PARP), and JNK 
activation, leading to apoptosis. The pan-caspase inhibitor BOC-D-FMK blocked the PTX-induced apoptosis but had no effect on cytochrome $\mathrm{C}$ release, suggesting that cytochrome $\mathrm{c}$ had been released before caspase activation. Moreover, both pharmacological JNK inhibitors SP600125 and JNK siRNA dramatically blocked PTX-induced apoptosis, cytochrome c release, caspase 3 , and PARP cleavage. These findings demonstrate that JNK activation plays a critical role in the induction of apoptosis mediated by PTX in human leukemia cell lines and CLL patient-derived primary cancer cells, and this event is upstream of cytochrome c release, caspase 3 , and PARP cleavage.

Key words: Paclitaxel; Apoptosis; Leukemia; c-Jun N-terminal kinase

\section{INTRODUCTION}

Paclitaxel (PTX; Figure 1) is a taxane that is derived from the bark of the Pacific yew tree Taxus brevifolia and was first shown to have anti-tumor activity in 1971 by Wani et al. PTX may be used alone or in combination with other chemotherapy agents to treat many different types of cancer, including leukemia, lymphoma, and cancers of the head, neck, breast, esophagus, stomach, bladder, prostate, endometrium (uterus), and cervix (Wani et al., 1971; Rowinsky, 1993; Roth, 1995; McGuire et al., 1996; Seidman et al., 1996; Younes et al., 1997; Fountzilas et al., 1999; Kelly et al., 2001; Markman and Fowler, 2004; Chang et al., 2005; Ilson et al., 2007; Ward et al., 2007). The principal mechanism of its anti-cancer effect is to disrupt microtubule stability, thereby preventing cell growth (Schiff et al., 1979; Schiff and Horwitz, 1980, 1981; Baum et al., 1981). Studies have shown that the pharmacological action of PTX is exhibited in both a dose- and time-dependent manner (Kim et al., 2007). In vitro, different modes of action have been established for PTX according to its concentration (Hernández-Vargas et al., 2007). Lu et al. (2005) reported that caspase3-dependent apoptosis induced by PTX was examined in HL-60 leukemia cells, and growth of the treated cells was arrested at the G2/M phase. In another study, Yu et al. (2001) demonstrated that the mitogen-activated protein kinase/mitogen-activated protein kinase (MEK/MAPK) cascade was involved in the anti-cancer activity of PTX. PTX and subsequent exposure of MEK/MAPK inhibitors together induced perturbations in ERK1/2 MAPK and p38 MAPK signaling cascades in U937 leukemia cells (Yu et al., 2001). However, the molecular mechanisms of taxane-dependent cytotoxicity are not fully understood, especially the action of PTX on the c-Jun N-terminal kinase (JNK)-apoptosis pathway. Furthermore, the effect of PTX on patients' primary chronic lymphocytic leukemia (CLL) cells has not been investigated. In this report, we demonstrated that JNK activation plays a critical role in the production of apoptosis mediated by PTX in leukemia cells including CLL primary cells, and this event occurs upstream of cytochrome c release, caspase, and poly (ADPribose) polymerase (PARP) cleavage.

\section{MATERIAL AND METHODS}

\section{Cell culture and drug treatment}

The human monocytic leukemia cell line U937 and CLL primary leukemia cells were isolated from the peripheral blood of a patient with diffuse histocytic lymphoma and a CLL patient, re- 
spectively, as described elsewhere (Gallagher et al., 1979; Yu et al., 2001). Cells were maintained as described previously (Yu et al., 2001). Jurkat T-cell acute leukemia cells were purchased from American Type Culture Collection (Manassas, VA, USA). All cells described above were cultured in RPMI 1640 medium supplemented with sodium pyruvate, minimum essential medium essential vitamins, L-glutamine, penicillin/streptomycin, and 10\% heat-inactivated fetal bovine serum (Gibco BRL, Grand Island, NY, USA) under a humidified atmosphere and $5 \% \mathrm{CO}_{2}$ at $37^{\circ} \mathrm{C}$. Cells were passaged twice a week and were prepared for experimental procedures when they were in log phase growth. PTX, BOC-D-FMK (BOC), and SP600125 were purchased from Sigma-Aldrich (St. Louis, MO, USA). A stock solution of each drug was made by dissolving each in dimethyl sulfoxide (DMSO, Sigma-Aldrich) and storing at $20^{\circ} \mathrm{C}$, avoiding light. Sequential dilutions were made using cell culture medium to prepare the working concentrations and DMSO was adjusted to $0.1 \%$ in each dose (0.1\% DMSO was used as vehicle control in all experiments). Cells were cultured in T25 flasks with the medium described above. Cells $\left(2 \times 10^{5}\right)$ were plated as a starting cell number and cells were exposed to either PTX or SP600125 the next day with different doses or time courses as described below. At the given time points, all cells including the floating apoptotic cells were collected and centrifuged at $1000 \mathrm{rpm}$ for $5 \mathrm{~min}$ at $4^{\circ} \mathrm{C}$ on a Beckman Coulter Allegra $6 \mathrm{R}$ bench top centrifuge (Beckman Coulter, Fullerton, CA, USA). Cells were then twice washed with ice-cold phosphate-buffered saline (PBS), thus preparing them for analysis.

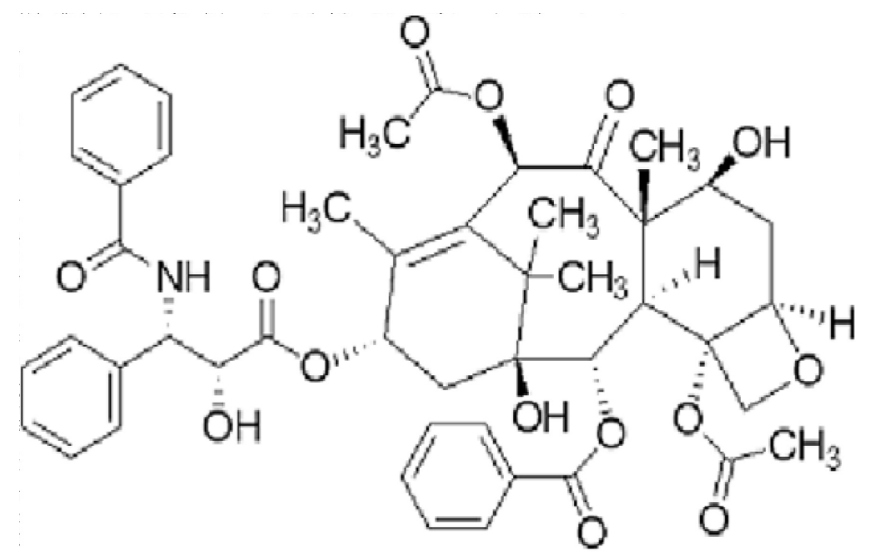

Figure 1. Structure of paclitaxel.

\section{JNK-1 knockdown experiment}

A JNK-1-specific siRNA (5'-GCAGAAGCAAACGTGACAACA-3') and a negative control siRNA were purchased from Dharmacon-Thermo Scientific (Dharmacon Inc., Chicago, IL, USA). The siRNA transfection procedures were performed according to the manufacturer instructions.

\section{Mitochondrial membrane potential determination}

Mitochondrial membrane potential was determined according to Yu et al. (2001) using 3,3-dihexyloxacarbocyanine iodide (Calbiochem, San Diego, CA, USA) and samples were analyzed on a BD flow cytometer (Becton-Dickinson, San Jose, CA, USA). 


\section{Cell apoptosis analysis}

Cells were harvested after exposure to drugs at various doses or time points or siRNA transfection. For the apoptosis assay, cells were prepared using an Annexin V-PE apoptosis detection kit I (BD Biosciences Pharmingen, San Diego, CA, USA) according to the manufacturer instruction. Briefly, cells were washed twice with ice-cold PBS and then re-suspended in $1 \mathrm{X}$ binding buffer at a concentration of $1 \times 10^{6}$ cells $/ \mathrm{mL}$. One hundred microliters of cell suspension containing $1 \times 10^{5}$ cells was transferred to a $5-\mathrm{mL}$ BD centrifuge tube, and then $5 \mu \mathrm{L}$ Annexin V-PE and $5 \mu \mathrm{L}$ 7-AAD solution were added into the tube. Cells were incubated with both reagents for $15 \mathrm{~min}$ at room temperature $\left(23^{\circ} \mathrm{C}\right)$ in the dark after gentle vortexing. Lastly, $400 \mu \mathrm{L} 1 \mathrm{X}$ binding buffer was added to the cells, apoptotic cells were detected on a BD Facscan flow cytometer (Becton Dickinson), and data were analyzed using the WinList SP4 software. Experiments were repeated in triplicate.

\section{Western blotting}

Cell lysates were prepared utilizing cell lysis buffer $(40 \mathrm{mM}$ phosphate buffer, $\mathrm{pH} 7.2$, $250 \mathrm{mM}$ sodium chloride ( $\mathrm{NaCl}$ ), $50 \mathrm{mM}$ sodium fluoride (NaF), $5 \mathrm{mM}$ EDTA, 1\% Triton X-100, and $1 \%$ deoxycholate) and a $1 \%$ protease and phosphatase inhibitor cocktail was added immediately before use (Sigma-Aldrich). The protein assay was carried out utilizing the Bradford method (Bio-Rad, Hercules, CA, USA) on a Beckman Coulter DU640 spectrophotometer. Western blot analysis was performed using $50 \mu \mathrm{g}$ protein. Protein was resolved over $10-15 \%$ sodium dodecyl sulfate polyacrylamide gel electrophoresis (SDS-PAGE) according to the molecular weight of the individual antibody used in the experiments, and transferred to a polyvinylidene difluoride membrane. The blot was blocked in blocking buffer ( $5 \%$ nonfat dry milk, $10 \mathrm{mM} \mathrm{Tris,} \mathrm{pH} 7.5$, $10 \mathrm{mM} \mathrm{NaCl}$, and $0.1 \%$ Tween 20) for $1 \mathrm{~h}$ at room temperature. Each membrane was then incubated with one of the following antibodies: rabbit anti-procaspase 3, rabbit anti-PARP and anti-cleaved PARP, mouse anti-cleaved PARP, rabbit anti-phospho JNK1/2, rabbit anti-JNK, rabbit anti-phospho-c-Jun, rabbit anti-cleaved caspase 3 (each at 1:1000 dilutions) (Cell Signaling Technology Inc., Danvers, MA, USA), and mouse anti-tubulin (1:5000) (Sigma-Aldrich) monoclonal antibodies; followed by incubation with a goat anti-rabbit or goat anti-mouse horseradish peroxidase-conjugated secondary antibody (KPL, Gaithersburg, MD, USA) at a dilution of 1:5000 at room temperature for $1 \mathrm{~h}$. Protein bands were visualized by the SuperSignal West Pico Chemiluminescent Substrate kit obtained from Pierce (Rockford, IL, USA) and exposed with Kodak X-ray film (Eastman Kodak, Rochester, NY, USA).

\section{Statistical analysis}

The apoptotic rates of Jurkat cells treated with different doses of PTX on U937 were analyzed by one-way analysis of variance (ANOVA), and the time course data were analyzed by repeated measures ANOVA. The mean gray value of the western blot bands was collected by the Image J Software, and the relative value to tubulin protein was analyzed by the $t$-test. The apoptosis of leukemia cells due to pan-caspase inhibitor BOC and JNK inhibitor SP600125 and the cells transfected with JNK-1 siRNA were analyzed by the $t$-test. 


\section{RESULTS}

\section{PTX induces apoptosis in leukemia cell lines in dose- and time-dependent manners}

Our results indicate that PTX mediated apoptosis in leukemia cells in dose- and time-dependent manners (Figure 2). As seen in Figure 2, monocytic leukemia U937 cells and Jurkat cells are both sensitive to PTX. In U937 cells, less than 5 nM PTX induced more than $50 \%$ of cells to be apoptotic while in Jurkat cells, $10 \mathrm{nM}$ was required (Figure 2A and B) after 24-h treatment, with significant differences between the control group $(P<0.05)$. Although both cells are very sensitive to PTX, U937 cells are more sensitive to PTX than Jurkat cells based on Annexin-V staining. Figure $2 \mathrm{C}$ shows the time-dependent pattern where PTX induced apoptosis in $50 \%$ or more of the cells in less than $18 \mathrm{~h}$ and significance was observed as early as $6 \mathrm{~h}(\mathrm{P}<0.05)$.
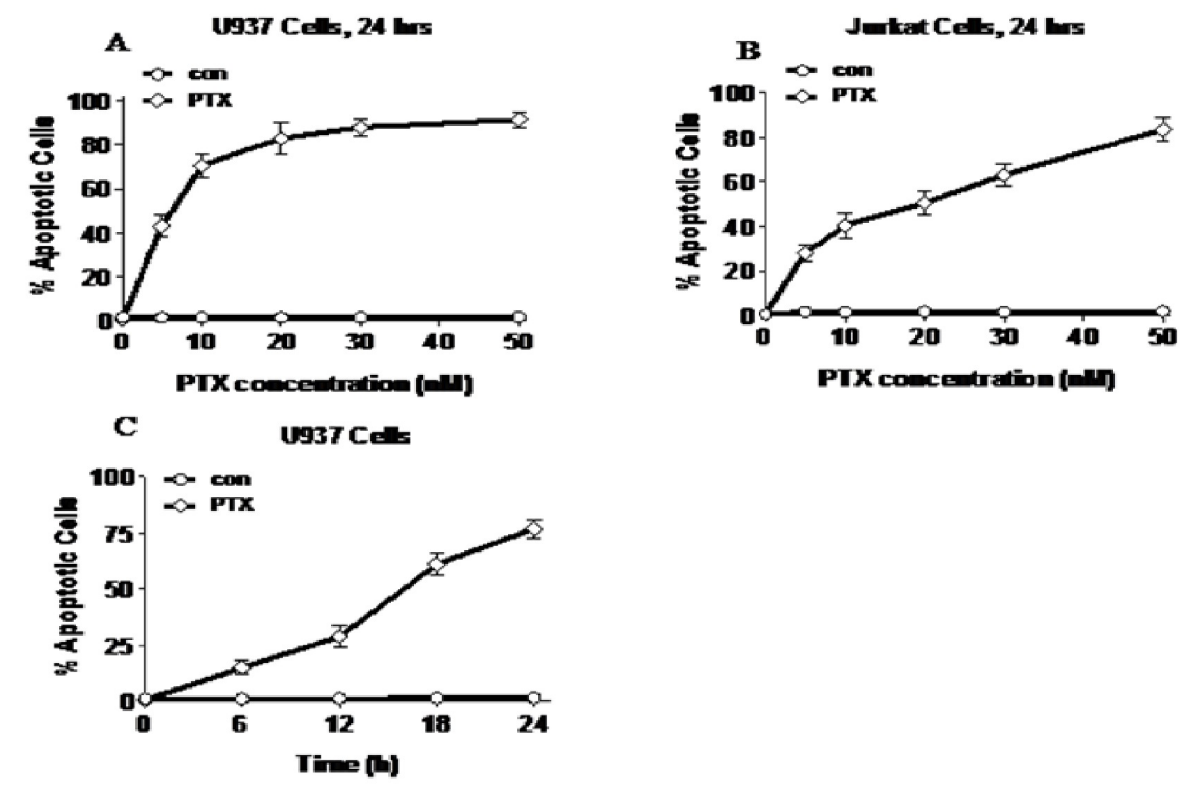

Figure 2. Paclitaxel-induced apoptosis in leukemia cells (U937 and Jurkat cells) in dose- and time-dependent manners (Annexin-V analysis). A. and B. Dose-dependent effect of PTX on U937 and Jurkat cells. C. Time-dependent effect of PTX on U937 cells.

\section{PTX induces apoptosis via cytosolic cytochrome c release, caspase 3 activation, and PARP cleavage}

In this study, our results also showed that leukemia cells exposed to PTX (Figure 3) exhibited mitochondria instability (Figure 3A). In U937 cells, 20 nM PTX dramatically increased cytochrome $\mathrm{c}$ release while at the same time reducing procaspase 3 after $24 \mathrm{~h}$ treatment (Figure 3B), and the statistical results are shown in Table 1. All the data are relative values based on the expression of tubulin. Furthermore, the cleaved fragment of PARP was also observed following the same treatment, dose, and time point. The pan-caspase inhibitor BOC blocked PTX-induced procaspase 3 activation and thus inhibited apoptosis (Figure $3 \mathrm{C}$ and D). The apoptosis rate of the 
control cells was $1.3 \pm 0.04 \%$, with the PTX cells exhibiting a significantly higher rate of $59.8 \pm$ $8.31 \%(P=0.013)$. The $B O C$ cells had an apoptosis rate of $1.4 \pm 0.04 \%$, which was similar to the control. The PTX + BOC cells had an apoptosis rate of $8.9 \pm 2.9 \%$, which was much less than PTX $(P=0.027)$. It is notable that PTX also antagonized BOC's inhibitory effect on caspase 3 activation and cytochrome $c$ release (Figure 3D), and the concentrations of CysC and procaspase 3 are shown in Table 2 (based on the expression of tubulin) $(P<0.05)$.
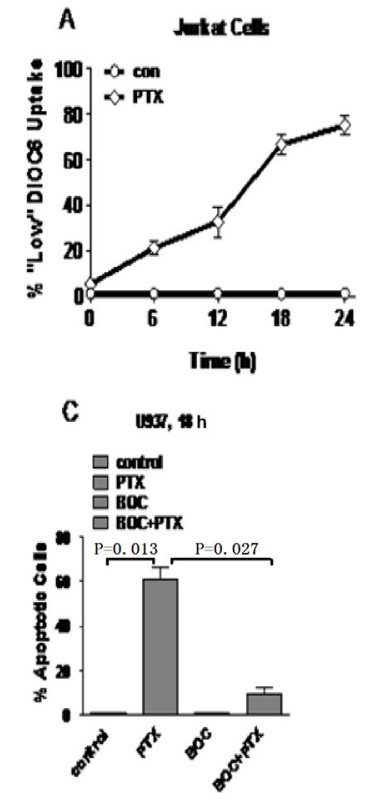

\section{B $\quad$ v937, 24h}

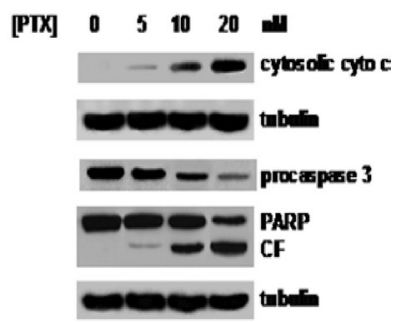

D $4937,18 \mathrm{~h}$

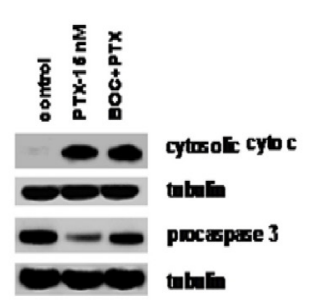

Figure 3. Effect of PTX on mitochondrial events in leukemia cells. A. Jurkat cells were exposed to $15 \mathrm{nM}$ PTX for various times and mitochondrial potency was measured utilizing flow cytometry (see Methods). B. U937 cells were exposed to PTX at various doses and cytosolic cytochrome c, procaspase 3 , and PARP and its cleaved fragment were analyzed by western blot. C. Effect of pan-caspase inhibitor BOC on apoptosis in U937 cells. D. Cells were exposed to $15 \mathrm{nM}$ PTX or $50 \mu \mathrm{M} \mathrm{BOC}$ alone or in combination for $18 \mathrm{~h}$. Apoptosis was analyzed by flow cytometry.

Table 1. Concentration of CysC/procaspase 3/PARP and its cleaved fragment in U937 cells at $24 \mathrm{~h}$ (based on the expression of tubulin).

\begin{tabular}{l|c|c|c|c}
\hline Protein & PTX $=0$ & PTX $=5 \mathrm{nM}$ & PTX $=10 \mathrm{nM}$ & PTX $=20 \mathrm{nM}$ \\
\hline CysC & $0^{*}$ & $0.0017 \pm 0.0004^{*}$ & $0.13 \pm 0.02^{*}$ & $0.21 \pm 0.03$ \\
\hline Procaspase 3 & $0.52 \pm 0.11^{*}$ & $0.39 \pm 0.08^{*}$ & $0.22 \pm 0.07^{*}$ & $0.07 \pm 0.03$ \\
\hline PARP & $0.97 \pm 0.22^{*}$ & $0.93 \pm 0.17^{*}$ & $0.89 \pm 0.15^{*}$ & $0.31 \pm 0.12$ \\
\hline Cleaved fragment & $0^{*}$ & $0.0009 \pm 0.0003^{*}$ & $0.09 \pm 0.01^{*}$ & $0.47 \pm 0.17$ \\
\hline
\end{tabular}

Compared with PTX $=20 \mathrm{nM},{ }^{*} \mathrm{P}<0.05$. 
Table 2. Concentration of $\mathrm{CysC} /$ procaspase 3 in U937 cells at $18 \mathrm{~h}$ (based on the expression of tubulin).

\begin{tabular}{l|c|c|c}
\hline Protein & Control & PTX $=15 \mathrm{nM}$ & PTX+BOC \\
\hline CysC & $0.0003 \pm 0.0001$ & $0.91 \pm 0.17^{*}$ & $0.78 \pm 0.16^{* \Delta}$ \\
\hline Procaspase 3 & $0.89 \pm 0.12$ & $0.10 \pm 0.03^{*}$ & $0.34 \pm 0.05^{* \Delta}$ \\
\hline
\end{tabular}

Compared with control, ${ }^{*} \mathrm{P}<0.05$; compared with $\mathrm{PTX}=15 \mathrm{nM}, \stackrel{\Delta}{\mathrm{P}}<0.05$.

\section{PTX activated JNK, which is a key event in cell apoptosis in the leukemia cell line} and patient-derived CLL cells

Our study showed that in U937 leukemia cells, phospho-JNK1/2 and phosphor-C-Jun were both elevated by PTX after 18-h treatment in a dose-dependent manner, starting at $10 \mathrm{nM}$, and the effects were more remarkable at $20 \mathrm{nM}$ (Figure 4A). The concentrations are shown in Table 3, with significant differences between PTX $=20 \mathrm{nM}$ and PTX $=0 / 5 / 10 \mathrm{nM}$ (based on the expression of tubulin). The pan-caspase inhibitor BOC did not inhibit the JNK phosphorylation effect of PTX (Figure 4B and Table 4) (based on the expression of tubulin).

A U937, $18 \mathrm{~h}$

\section{PTX (II) $0 \quad 5 \quad 10 \quad 20$}

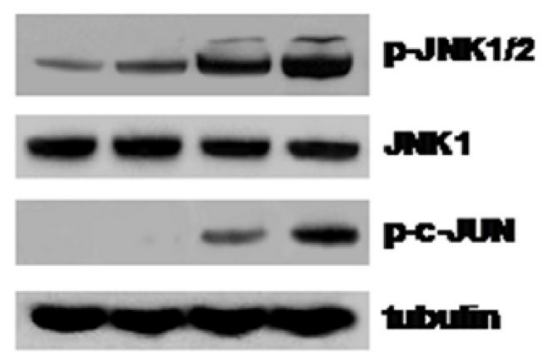

B Us3,18 h

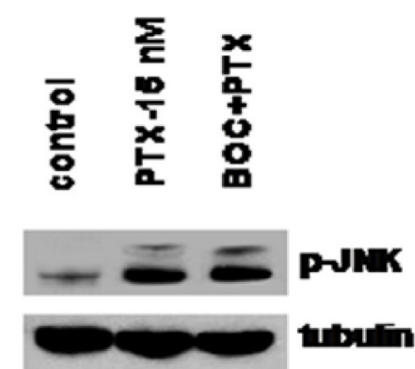

Figure 4. Effect of PTX on JNK activation and c-Jun phosphorylation in leukemia cells. U937 cells were exposed to different doses of PTX for $18 \mathrm{~h}$. The phosphorylated JNK and c-Jun, cytosolic cytochrome c, and procaspase 3 were analyzed by western blot. A. Various doses of PTX were used for $18 \mathrm{~h}$. B. Cells were exposed to $15 \mathrm{nM}$ PTX alone or in combination with $\mathrm{BOC}(50 \mu \mathrm{M})$ for $18 \mathrm{~h}$.

Table 3. Concentration of $p-J N K 1 / 2$, JNK1 and p-C-JUN in U937 cells at $18 \mathrm{~h}$ (based on the expression of tubulin).

\begin{tabular}{l|c|c|c|c}
\hline Protein & PTX $=0$ & PTX $=5 \mathrm{nM}$ & PTX $=10 \mathrm{nM}$ & PTX $=20 \mathrm{nM}$ \\
\hline p-JNK1/2 & $0.08 \pm 0.02^{*}$ & $0.18 \pm 0.04^{*}$ & $0.41 \pm 0.14^{*}$ & $0.76 \pm 0.23$ \\
\hline JNK-1 & $0.78 \pm 0.22$ & $0.82 \pm 0.23$ & $0.77 \pm 0.19$ & $0.80 \pm 0.25$ \\
\hline p-c-JUN & $0^{*}$ & $0^{*}$ & $0.11 \pm 0.03^{*}$ & $0.29 \pm 0.08$ \\
\hline
\end{tabular}

Compared with $\mathrm{PTX}=20 \mathrm{nM},{ }^{*} \mathrm{P}<0.05$. 
Table 4. Concentration of p-JNK in U937 cells at $18 \mathrm{~h}$ (based on the expression of tubulin).

\begin{tabular}{l|c|c|c}
\hline Protein & Control & PTX $=15 \mathrm{nM}$ & PTX+BOC \\
\hline p-JNK & $0.03 \pm 0.007$ & $0.56 \pm 0.08^{*}$ & $0.55 \pm 0.10^{*}$ \\
\hline
\end{tabular}

Compared with control, * $\mathrm{P}<0.05$.

However, our study showed that JNK inhibitor SP600125 decreased the apoptotic induction of PTX in human leukemia cells (Figure $5 \mathrm{~A}$ ). In the control cells, the apoptosis rate was $1.1 \pm 0.03 \%$, while in PTX cells the apoptosis rate was $57.9 \pm 7.22 \%$, which was significantly different $(P=0.019)$. In SP600125 cells, the apoptosis rate was $1.2 \pm 0.02 \%$, which was similar to the control. In the PTX + SP600125 cells, the apoptosis rate was $2.9 \pm 0.9 \%$, which was much less than the PTX cells $(\mathrm{P}=$ 0.012). PTX (15 nM) induced JNK and caspase 3 activation (procaspase 3 reduced) and c-Jun phosphorylation, and cytochrome c release after 18-h treatment. Nevertheless, SP600125 blocked JNK activation, c-Jun phosphorylation, and the release of cytochrome c from mitochondria and decreased caspase 3 activation (Figure 5B). The concentrations are shown in Table 5.

In addition, cells transfected with JNK-1 siRNA exhibited markedly lowered levels of JNK-1 expression and phosphorylation. Knockdown of JNK-1 largely blocked caspase 3 activation and cytochrome c release (data not shown), as well as apoptosis (Figure 5C and D). In control-siRNA cells, the apoptosis rate was $1.2 \pm 0.03 \%$, whereas in control-siRNA + PTX, the apoptosis rate was $72.4 \pm 11.48 \%$, which was significantly higher than the control-siRNA $(P=0.000)$. In JNK-1-siRNA cells, the apoptosis rate was $6.1 \pm 0.87 \%$, which was similar to the control-siRNA, and in JNK1 -siRNA + PTX, the apoptosis rate was $28.9 \pm 9.1 \%$, which was much less than the control-siRNA + PTX cells $(P=0.046$; Table 6).
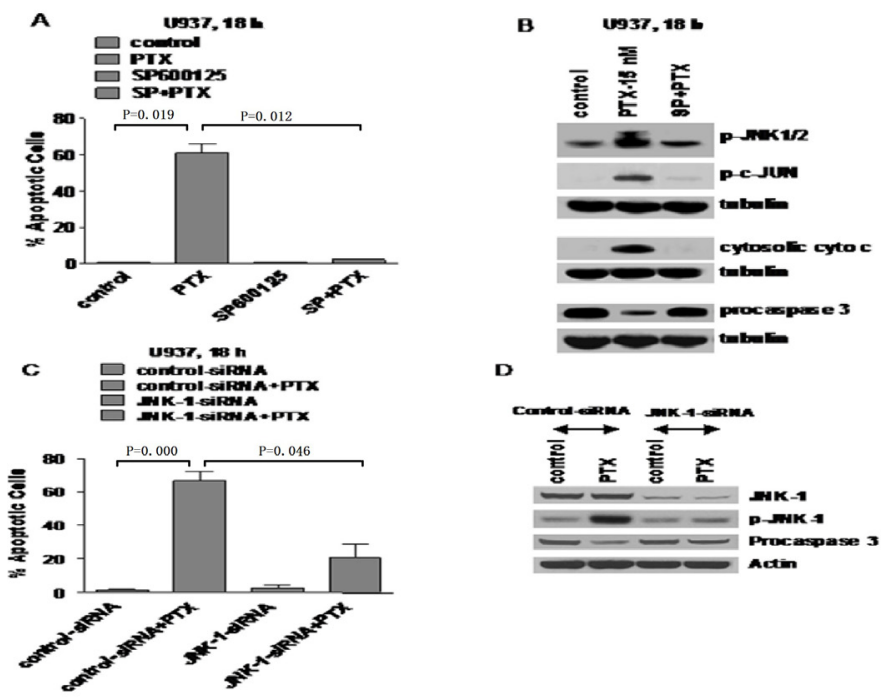

Figure 5. JNK inhibitor SP600125 or JNK-1 knockdown diminished PTX-induced apoptosis in leukemia cells. A. U937 cells were exposed to $15 \mathrm{nM}$ PTX and $15 \mu \mathrm{M}$ SP600125 alone or in combination for $18 \mathrm{~h}$. Flow cytometry was carried out for apoptosis analysis. B. Western blot analysis for phosphor-JNK, phosphor-C-Jun, cytosolic cytochrome c, and procaspase 3 after exposure to 15 nM PTX or PTX combined with SP600125 for $18 \mathrm{~h}$ in U937 cells. C. U937 cells were transfected with JNK-1 siRNA SMART pool for $48 \mathrm{~h}$, followed by 18-h treatment with PTX. Apoptotic cells were analyzed by Annexin-V-PE staining. D. Western blot was carried out for indicated markers for further verification. 
Table 5. Concentration of p-JNK1/2, p-C-JUN, CysC, and procaspase 3 in U937 cells at $18 \mathrm{~h}$ (based on the expression of tubulin).

\begin{tabular}{l|c|c|c}
\hline Protein & Control & PTX $=15 \mathrm{nM}$ & PTX+SP \\
\hline p-JNK1/2 & $0.10 \pm 0.02$ & $0.45 \pm 0.08^{*}$ & $0.26 \pm 0.09^{\Delta}$ \\
\hline p-c-JUN, & 0 & $0.20 \pm 0.04^{*}$ & $0.001 \pm 0.0001^{\Delta}$ \\
\hline CysC & 0 & $0.76 \pm 0.18^{*}$ & $0.0003 \pm 0.0001^{\Delta}$ \\
\hline Procaspase 3 & $0.89 \pm 0.13$ & $0.14 \pm 0.02^{*}$ & $0.72 \pm 0.17^{\rho}$ \\
\hline
\end{tabular}

Compared with control, ${ }^{*} \mathrm{P}<0.05$; compared with $\mathrm{PTX}=15 \mathrm{nM},{ }^{\Delta} \mathrm{P}<0.05$.

Table 6. Concentration of JNK-1, p-JNK-1, and procaspase 3 in U937 cells at $18 \mathrm{~h}$ (based on the expression of actin).

\begin{tabular}{l|c|c|c|c}
\hline Protein & Control-siRNA & Control-siRNA+PTX & JNK-1-siRNA & JNK-1-siRNA+PTX \\
\hline JNK-1 & $0.38 \pm 0.10$ & $0.36 \pm 0.11$ & $0.021 \pm 0.003^{* \Delta}$ & $0.020 \pm 0.002^{* \Delta}$ \\
\hline p-JNK-1 & $0.13 \pm 0.02$ & $0.54 \pm 0.21$ & $0.20 \pm 0.09^{\Delta}$ & $0.28 \pm 0.08^{\Delta}$ \\
\hline Procaspase 3 & $0.27 \pm 0.03$ & $0.12 \pm 0.04$ & $0.28 \pm 0.04$ & $0.19 \pm 0.03$ \\
\hline
\end{tabular}

Compared with control-siRNA, ${ }^{*} \mathrm{P}<0.05$; compared with control-siRNA+PTX, ${ }^{\Delta} \mathrm{P}<0.05$.

In patient-derived primary CLL cells, PTX also induced cell apoptosis. The primary CLL cells were more susceptible to PTX in terms of apoptosis than other leukemia cells used in this study. The JNK inhibitor SP600125 inhibited cell apoptosis, and this was partially recovered by PTX. This result is similar to that in the leukemia cell lines described above (Figure 6A). In the control cells, the apoptosis rate was $0.9 \pm 0.02 \%$, while in PTX cells, the apoptosis rate was significantly greater $(39.5 \pm 6.34 \%)(P=0.034)$. In SP600125 cells, the apoptosis rate was $4.3 \pm 0.78 \%$. In SP + PTX, the apoptosis rate was $11.9 \pm 2.1 \%$, significantly less than PTX cells $(P=0.047)$. Figure 6B shows the effect of PTX and SP600125 on c-Jun phosphorylation and caspase 3 cleavage in primary CLL cells, similar to that of leukemia cell lines mentioned previously (Table 7).

A

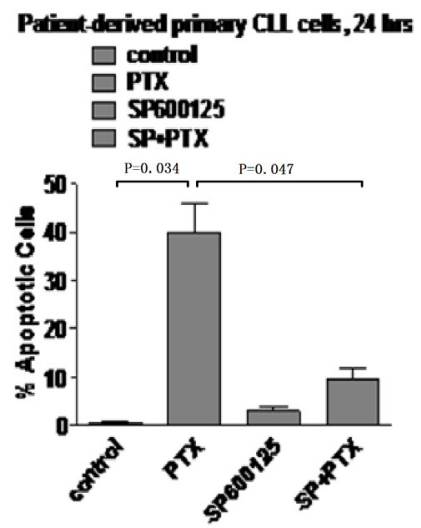

B

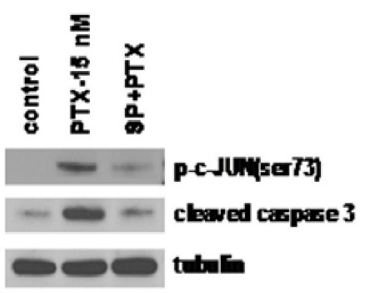

Figure 6. Effect of PTX, SP600125, and PTX combined with SP600125 on apoptosis, c-Jun phosphorylation, and caspase 3 cleavage in patient-derived primary CLL cells. A. Effect of either $15 \mathrm{nM}$ PTX or $15 \mu \mathrm{M}$ SP600125 or the combination of both on apoptosis. B. Effect of $15 \mathrm{nM}$ PTX in combination with $15 \mu \mathrm{M}$ SP 600125 for $24 \mathrm{~h}$ on phosphorc-Jun and cleaved caspase 3 in primary CLL cells. 
Table 7. Concentration of p-c-JUN and cleaved caspase 3 in patient-derived primary CLL cells, $24 \mathrm{~h}$ (based on the expression of tubulin).

\begin{tabular}{l|c|c|c}
\hline Protein & Control & PTX $=15 \mathrm{nM}$ & PTX+SP \\
\hline p-c-JUN & 0 & $0.24 \pm 0.07^{*}$ & $0.007 \pm 0.002^{\Delta}$ \\
\hline Cleaved caspase 3 & $0.008 \pm 0.001$ & $0.79 \pm 0.17^{*}$ & $0.010 \pm 0.003^{*}$ \\
\hline
\end{tabular}

Compared with control, ${ }^{*} \mathrm{P}<0.05$; compared with $\mathrm{PTX}=15 \mathrm{nM},{ }^{\Delta} \mathrm{P}<0.05$.

\section{DISCUSSION}

To further elucidate the molecular mechanisms underlying PTX-induced apoptosis in leukemia cells, specifically the role of the JNK signaling pathway, we performed the present study focusing first on the dose- and time-dependent effects of PTX treatment on these cells. Second, we observed mitochondrion event changes, cytochrome c release, caspase 3 activation, and PARP cleavage in different leukemia cell lines and primary CLL cells. Lastly, the underlying mechanism of the JNK signaling pathway and its role in PTX-induced apoptosis in the leukemia cells was investigated.

Dose- and time-dependent effects are important to take into account when evaluating the potency of a chemotherapeutic agent. Previous studies have shown that PTX inhibited cell growth in dose- and time-dependent manners in some solid tumor cells (Wang et al., 1999; Park et al., 2004) as well as in some leukemia cells (Huisman et al., 2002). In this study, our purpose was to further understand whether (in addition to leukemia cell lines) PTX has any effect and if so, its potency on human primary CLL cells. Apoptosis is the fundamental mechanism by which anticancer drugs execute their effect. Our results indicate that PTX mediated apoptosis in leukemia cells in a dose- and time-dependent manner. As seen in the results, monocytic leukemia U937 cells and Jurkat cells are both sensitive to PTX. However, the U937 cells had a more desirable reaction to PTX treatment than Jurkat cells. It is known that different subtypes of certain cancer tumors have clinically different reactions to specific chemotherapeutic agents. Thus, this result further demonstrates the importance of chemotherapeutic agent screening and dose testing both in vitro and in vivo.

Cytochrome $\mathrm{c}$ is the carrier of electrons in the mitochondria of cells. Together with the mitochondria, it plays a critical role in apoptosis. The release of cytochrome $c$ from mitochondria into the cytoplasm allows it to associate with Apaf- 1 to form the seven-armed apoptosome. This apoptosome complex activates the protein-cutting caspases that begin the heavy work of cell death via apoptosis (Jeffery, 1999; Desagher and Martinou, 2000). In this study, our results also showed that exposure of leukemia cells to PTX exhibited mitochondria instability, resulting in the release of cytochrome $\mathrm{c}$ from mitochondria into the cytoplasm. It is known that cytochrome $\mathrm{c}$ is the activator of some apoptosis-related elements in the apoptotic cascade, such as procaspase 3 and PARP. In the leukemia cell lines, 20 nM PTX dramatically increased cytochrome c release while reducing procaspase 3 (caspase 3 activated) remarkably at the same time after 24-h treatment. The same dose and time of PTX treatment led to the cleavage of PARP, thus reducing the DNA repair machinery in the cells. Interestingly, the pan-caspase inhibitor BOC blocked PTX-induced procaspase 3 cleavage thereby diminishing the apoptotic effect induced by PTX. These results suggest that mitochondrial instability leading to the release of cytochrome c, activation of caspase 3 , and cleavage of PARP are involved in the apoptotic events induced by PTX in leukemia cells.

JNKs are mitogen-activated protein kinases, which are responsive to stress stimuli such as cytokines, ultraviolet irradiation, heat shock, and osmotic shock, and are involved in T cell differentiation and apoptosis. JNK-1 has been found to regulate Jun protein turnover by phosphoryla- 
tion and protein ubiquitination. JNK also modifies the activity of numerous proteins that reside at the mitochondria or act in the nucleus by phosphorylation of its target proteins (Vlahopoulos and Zoumpourlis, 2004; Waetzig and Herdegen, 2005). JNK activation has been shown in PTX-treated solid tumor cells (Lee et al., 1998; Kolomeichuk et al., 2008). However, the detailed mechanism of JNK in apoptosis procedures remains largely unclear (Shiah et al., 2001; Ohtsuka et al., 2003; Brichese et al., 2004; Wang et al., 2006; Zhang et al., 2006; Small et al., 2007; Selimovic et al., 2008). Furthermore, studies of JNK's function in PTX-induced apoptosis in leukemia are rare, and only a few have been performed in the past decade (Kang et al., 2000; Yu et al., 2001). Our study showed that in U937 leukemia cells, exposure to PTX for $18 \mathrm{~h}$ resulted in JNK1/2 and c-Jun phosphorylation. These effects were visible at $10 \mathrm{nM}$ and were more remarkable at $20 \mathrm{nM}$. In the meantime, the level of cytosolic cytochrome $c$ was elevated significantly by PTX. The pan-caspase inhibitor BOC was not able to block PTX's effect on cytochrome c release. Procaspase 3 was decreased (caspase 3 activation) in cells treated with PTX alone while the pan-caspase inhibitor BOC blocked PTX's effect on caspase 3 activation. These results indicate that the apoptosis effect of PTX is caspase-dependent. Furthermore, these results suggest that cytochrome $c$ release and JNK activation are the upstream events of caspase activation via PTX.

Since the activation of JNK1/2 (phosphorylated form) and phospho-C-Jun was observed in our study, we determined whether the JNK-C-Jun signaling pathway is involved and if it could be the key event mediating the effects of PTX on leukemia cells. We utilized the JNK inhibitor SP600125 as well as JNK-1 knockdown by transfection of JNK-1 siRNA SMART pool into U937 cells to investigate the role of JNK activation in this study. Our results showed that SP600125 decreased the apoptotic induction of PTX in human leukemia cells. We observed significant JNK phosphorylation and caspase 3 activation (procaspase 3 reduction), as well as c-Jun phosphorylation and cytochrome c release after $18 \mathrm{~h}$ of PTX treatment at $15 \mathrm{nM}$. However, SP600125 blocked the JNK activation, c-Jun phosphorylation, and the release of cytochrome $c$ from mitochondria and decreased caspase 3 activation. Furthermore, cells transfected with JNK-1 siRNA markedly reduced JNK-1 expression and therefore reduced phospho status as well. Knockdown of JNK1 blocked caspase 3 activation (procaspase 3 remained unaltered), cytochrome c release (data not shown), and apoptosis. Our results suggested that PTX activated JNK, and the latter further phosphorylated its downstream target c-Jun. It is known that phosphorylated c-Jun enhances its turnover, thus reducing its binding capability to DNA domain in proliferation-related genes as a transcriptional factor, leading to cell apoptosis.

As a potential translational study, we investigated PTX's ability to induce apoptosis in patient-derived primary CLL cells. We found that PTX also significantly induced CLL cell apoptosis. Interestingly, we determined that primary CLL cells were more susceptible to PTX in the event of apoptosis than other leukemia cells used in this study. The JNK inhibitor SP600125 inhibited cell apoptosis and PTX partially recovered apoptosis, as observed in the other leukemia cells. Our results also showed that PTX and the JNK inhibitor SP600125 had similar effects on C-Jun phosphorylation and caspase 3 cleavage in primary CLL cells, as in the leukemia cell lines. These studies could be helpful as a guide in a clinical trial regarding PTX dosing in CLL patients. Our results regarding the mechanism of PTX in the apoptosis induction of leukemia cells can be described by the following: JNK activation and c-Jun phosphorylation $\rightarrow$ mitochondrial instability and cytochrome c release $\rightarrow$ PARP cleavage and caspase 3 activation $\rightarrow$ cell apoptosis.

Taken together, our results demonstrate that PTX induces apoptosis in both patient-derived primary CLL cells and leukemia cell lines in dose- and time-dependent manners. The critical molecular basis of PTX-inducing apoptosis is activation of the JNK cascade, leading to mitochon- 
drial instability and cytochrome c release, caspase activation, and PARP cleavage, finally bringing cells to apoptosis. Our findings provide the foundation for further investigations regarding PTX application in CLL therapy.

\section{Conflicts of interest}

The authors declare no conflict of interest.

\section{REFERENCES}

Baum SG, Wittner M, Nadler JP, Horwitz SB, et al. (1981). Taxol, a microtubule stabilizing agent, blocks the replication of Trypanosoma cruzi. Proc. Natl. Acad. Sci. USA 78: 4571-4575. http://dx.doi.org/10.1073/pnas.78.7.4571

Brichese L, Cazettes G and Valette A (2004). JNK is associated with Bcl-2 and PP1 in mitochondria: paclitaxel induces its activation and its association with the phosphorylated form of Bcl-2. Cell Cycle 3: 1312-1319. http://dx.doi.org/10.4161/ cc.3.10.1166

Chang HM, Kim TW, Ryu BY, Choi SJ, et al. (2005). Phase II study of paclitaxel and carboplatin in advanced gastric cancer previously treated with 5-fluorouracil and platinum. Jpn. J. Clin. Oncol. 35: 251-255. http://dx.doi.org/10.1093/jico/hyi077

Desagher S and Martinou JC (2000). Mitochondria as the central control point of apoptosis. Trends Cell Biol. 10: 369-377. http://dx.doi.org/10.1016/S0962-8924(00)01803-1

Fountzilas G, Stathopoulos G, Nicolaides C, Kalogera-Fountzila A, et al. (1999). Paclitaxel and gemcitabine in advanced nonnasopharyngeal head and neck cancer: a phase II study conducted by the Hellenic Cooperative Oncology Group. Ann Oncol. 10: 475-478. http://dx.doi.org/10.1023/A:1008397424359

Gallagher R, Collins S, Trujillo J, McCredie K, et al. (1979). Characterization of the continuous, differentiating myeloid cell line (HL-60) from a patient with acute promyelocytic leukemia. Blood 54: 713-733.

Hernández-Vargas H, Palacios J and Moreno-Bueno G (2007). Telling cells how to die: docetaxel therapy in cancer cell lines. Cell Cycle 6: 780-783. http://dx.doi.org/10.4161/cc.6.7.4050

Huisman C, Ferreira CG, Bröker LE, Rodriguez JA, et al. (2002). Paclitaxel triggers cell death primarily via caspase-independent routes in the non-small cell lung cancer cell line NCl-H460. Clin. Cancer Res. 8: 596-606.

Ilson DH, Wadleigh RG, Leichman LP and Kelsen DP (2007). Paclitaxel given by a weekly 1-h infusion in advanced esophageal cancer. Ann. Oncol. 18: 898-902. http://dx.doi.org/10.1093/annonc/mdm004

Jeffery CJ (1999). Moonlighting proteins. Trends Biochem. Sci. 24: 8-11. http://dx.doi.org/10.1016/S0968-0004(98)01335-8

Kang CD, Yoo SD, Hwang BW, Kim KW, et al. (2000). The inhibition of ERK/MAPK not the activation of JNK/SAPK is primarily required to induce apoptosis in chronic myelogenous leukemic K562 cells. Leuk. Res. 24: 527-534. http://dx.doi. org/10.1016/S0145-2126(00)00010-2

Kelly WK, Curley T, Slovin S, Heller G, et al. (2001). Paclitaxel, estramustine phosphate, and carboplatin in patients with advanced prostate cancer. J. Clin. Oncol. 19: 44-53.

Kim SH, Juhnn YS and Song YS (2007). Akt involvement in paclitaxel chemoresistance of human ovarian cancer cells. Ann. N. Y. Acad. Sci. 1095: 82-89. http://dx.doi.org/10.1196/annals.1397.012

Kolomeichuk SN, Terrano DT, Lyle CS, Sabapathy K, et al. (2008). Distinct signaling pathways of microtubule inhibitors-vinblastine and Taxol induce JNK-dependent cell death but through AP-1-dependent and AP-1-independent mechanisms, respectively. FEBS J. 275: 1889-1899. http://dx.doi.org/10.1111/j.1742-4658.2008.06349.x

Lee LF, Li G, Templeton DJ and Ting JP (1998). Paclitaxel (Taxol)-induced gene expression and cell death are both mediated by the activation of c-Jun NH2-terminal kinase (JNK/SAPK). J. Biol. Chem. 273: 28253-28260. http://dx.doi.org/10.1074/ jbc.273.43.28253

Lu KH, Lue KH, Liao HH, Lin KL, et al. (2005). Induction of caspase-3-dependent apoptosis in human leukemia HL-60 cells by paclitaxel. Clin. Chim. Acta 357: 65-73. http://dx.doi.org/10.1016/j.cccn.2005.02.003

Markman M and Fowler J (2004). Activity of weekly paclitaxel in patients with advanced endometrial cancer previously treated with both a platinum agent and paclitaxel. Gynecol. Oncol. 92: 180-182. http://dx.doi.org/10.1016/j.ygyno.2003.10.019

McGuire WP, Blessing JA, Moore D, Lentz SS, et al. (1996). Paclitaxel has moderate activity in squamous cervix cancer. A Gynecologic Oncology Group study. J. Clin. Oncol. 14: 792-795.

Ohtsuka T, Buchsbaum D, Oliver P, Makhija S, et al. (2003). Synergistic induction of tumor cell apoptosis by death receptor antibody and chemotherapy agent through JNK/p38 and mitochondrial death pathway. Oncogene 22: 2034-2044. http:// dx.doi.org/10.1038/sj.onc. 1206290 
Park SJ, Wu CH, Gordon JD, Zhong X, et al. (2004). Taxol induces caspase-10-dependent apoptosis. J. Biol. Chem. 279: 51057-51067. http://dx.doi.org/10.1074/jbc.M406543200

Roth BJ (1995). Preliminary experience with paclitaxel in advanced bladder cancer. Semin. Oncol. 22 (Suppl 6): 1-5.

Rowinsky EK (1993). Clinical pharmacology of Taxol. J. Natl. Cancer Inst. Monogr. 15: 25-37..

Schiff PB and Horwitz SB (1980). Taxol stabilizes microtubules in mouse fibroblast cells. Proc. Natl. Acad. Sci. USA 77: 15611565. http://dx.doi.org/10.1073/pnas.77.3.1561

Schiff PB and Horwitz SB (1981). Taxol assembles tubulin in the absence of exogenous guanosine 5'-triphosphate or microtubule-associated proteins. Biochemistry 20: 3247-3252. http://dx.doi.org/10.1021/bi00514a041

Schiff PB, Fant J and Horwitz SB (1979). Promotion of microtubule assembly in vitro by taxol. Nature 277: 665-667.http://dx.doi. org/10.1038/277665a0

Seidman AD, Hochhauser D, Gollub M, Edelman B, et al. (1996). Ninety-six-hour paclitaxel infusion after progression during short taxane exposure: a phase II pharmacokinetic and pharmacodynamic study in metastatic breast cancer. J. Clin. Oncol. 14: 1877-1884.

Selimovic D, Hassan M, Haikel Y and Hengge UR (2008). Taxol-induced mitochondrial stress in melanoma cells is mediated by activation of c-Jun N-terminal kinase (JNK) and p38 pathways via uncoupling protein 2. Cell. Signal. 20: 311-322. http:// dx.doi.org/10.1016/j.cellsig.2007.10.015

Shiah SG, Chuang SE and Kuo ML (2001). Involvement of Asp-Glu-Val-Asp-directed, caspase-mediated mitogen-activated protein kinase kinase 1 Cleavage, C-Jun $\mathrm{N}$-terminal kinase activation, and subsequent $\mathrm{Bcl}-2$ phosphorylation for paclitaxelinduced apoptosis in HL-60 cells. Mol. Pharmacol. 59: 254-262.

Small GW, Shi YY, Higgins LS and Orlowski RZ (2007). Mitogen-activated protein kinase phosphatase-1 is a mediator of breast cancer chemoresistance. Cancer Res. 67: 4459-4466. http://dx.doi.org/10.1158/0008-5472.CAN-06-2644

Vlahopoulos S and Zoumpourlis VC (2004). JNK: a key modulator of intracellular signaling. Biochemistry (Mosc.) 69: 844-854.

Waetzig $V$ and Herdegen $T$ (2005). Context-specific inhibition of JNKs: overcoming the dilemma of protection and damage. Trends Pharmacol. Sci. 26: 455-461.

Wang TH, Popp DM, Wang HS, Saitoh M, et al. (1999). Microtubule dysfunction induced by paclitaxel initiates apoptosis through both c-Jun N-terminal kinase (JNK)-dependent and -independent pathways in ovarian cancer cells. J. Biol. Chem. 274: 8208-8216. http://dx.doi.org/10.1074/jbc.274.12.8208

Wang TH, Chan YH, Chen CW, Kung WH, et al. (2006). Paclitaxel (Taxol) upregulates expression of functional interleukin-6 in human ovarian cancer cells through multiple signaling pathways. Oncogene 25: 4857-4866. http://dx.doi.org/10.1038/ sj.onc. 1209498

Wani MC, Taylor HL, Wall ME, Coggon P, et al. (1971). Plant antitumor agents. VI. The isolation and structure of taxol, a novel antileukemic and antitumor agent from Taxus brevifolia. J. Am. Chem. Soc. 93: 2325-2327. http://dx.doi.org/10.1021/ ja00738a045

Ward S, Simpson E, Davis S, Hind D, et al. (2007). Taxanes for the adjuvant treatment of early breast cancer: systematic review and economic evaluation. Health Technol. Assess. 11: 1-144. http://dx.doi.org/10.3310/hta11400

Younes A, Ayoub JP, Sarris A, Hagemeister F, et al. (1997). Paclitaxel activity for the treatment of non-Hodgkin's lymphoma: final report of a phase II trial. Br. J. Haematol. 96: 328-332. http://dx.doi.org/10.1046/j.1365-2141.1997.d01-2012.x

Yu C, Wang S, Dent P and Grant S (2001). Sequence-dependent potentiation of paclitaxel-mediated apoptosis in human leukemia cells by inhibitors of the mitogen-activated protein kinase kinase/mitogen-activated protein kinase pathway. Mol. Pharmacol. 60: 143-154.

Zhang X, Ling MT, Wang X and Wong YC (2006). Inactivation of Id-1 in prostate cancer cells: A potential therapeutic target in inducing chemosensitization to taxol through activation of JNK pathway. Int. J. Cancer 118: 2072-2081. http://dx.doi. org/10.1002/ijc.21592 